\title{
A Review of Intelligent Tutorial Systems in Computer and Web based Education
}

\author{
Luis Alfaro ${ }^{1}$, Claudia Rivera $^{2}$, Elisa Castañeda ${ }^{3}$, Jesus Zuñiga-Cueva ${ }^{4}$, María Rivera-Chavez $^{5}$, \\ Francisco Fialho ${ }^{6}$ \\ Universidad Nacional de San Agustín de Arequipa, Arequipa - Perú ${ }^{1,2,3,4}$ \\ Universidad Católica de Santa María, Arequipa - Perú ${ }^{5}$ \\ Universidad Federal de Santa Catarina, Florianopolis-SC - Brasil ${ }^{6}$
}

\begin{abstract}
ITS (Intelligent Tutoring Systems) are integrated and complex systems, designed and developed using approaches and methods of artificial intelligence (AI), for the resolution of problems and requirements of the teaching/learning activities in the field of education and training of students and the workforce based in computers an web based emerging resources. These systems can establish the level of student knowledge and the learning strategies used to improve the level of knowledge to support the detection and correction of student misconceptions. Their purpose is to contribute to the process of teaching and learning in a given area of knowledge, respecting the individuality of the student. In this paper, a review of intelligent tutorial systems (ITS) is presented, from the perspective of their application and usability in modern learning concepts. The methodology used was that of bibliographical review of classic works of the printed and digital literature in relation to ITS and e-Learning systems, as well as searches in diverse databases, of theses and works in universities and digital repositories. The main weakness of the research lies in the fact that the search was limited to documents published in the English, Spanish and Portuguese.
\end{abstract}

Keywords-Intelligent learning systems; computer assisted learning environments; web based education

\section{INTRODUCTION}

The various investigations into the design and development of Intelligent Environments for computer-aided design/learning, also known as ITS, were initiated approximately in the 1970s. Some authors, such as Carbonell [1], tried to combine methods of Artificial Intelligence (AI) with Computer Aided Instruction (CAI), to propose a system that would try to create an environment that would take into consideration the diversity of the various learning styles of the students, thus adapting to the individual requirements of those who would use the system. This type of software was called Intelligent Tutor or Intelligent Tutorial Systems. IACs and ITS are apparently in a similar type of application in education.

The study of ITS is an area of research on which a large number of researchers focused, working on topics that have strong relationships with various disciplines. Researchers interested in getting started in this field may have difficulty understanding the basics and methodologies used in ITS. These difficulties include understanding the functioning of ITS and their components, their functions, the main types of ITS, the Artificial Intelligence technologies involved, learning theories and their uses, differences in terms of interaction and behaviour, the importance and contributions of ITS in education, and their effectiveness.
This paper does not aim to focus on a specific topic or dimension of ITS, nor to visualize details that may require further study. After understanding the main concepts and ITS and their behaviors, a reader can review widely detailed and conventional sources such as Woolf [2], Ma et al. [3], Nwana [4], Shute et al. [5], and Murray [6], among other authors for further research. In Section II, the fundamentals of Intelligent Tutorial Systems are described; in Section III, a review of developed intelligent tutoring systems (ITS) in education is made, in Section IV, some developments are described and analyzed, in Section V, the discussion is made, and finally, in Section VI, the conclusions are established and the corresponding comments are made.

\section{Intelligent TUtorial Systems}

An ITS can be described as software that involves [3], [7]:

- A computer that encodes pedagogical domains and human teacher knowledge (trainer) as a good mechanism to communicate with other humans;

- A trainee who interacts with a computer to acquire some skills in those domains.

Burns [8], emphasizes that ITS research, especially considering teaching-learning theories, should address teaching strategies, taking into consideration individual differences. This research includes well-known works referred to by P. Lach [9], such as Clance's Guidon and his later reviews, Soloway and Johnson's; PROUST, Anderson and Boyle; ACT tutors, as well as Dillenbourg ETOILE [10] and many others, which proposed the characteristics of ITS and their abilities to diagnose misconceptions of the learner during the teaching process and, based on that diagnosis, provide subsidiary teaching to students. However, many psychological issues underlying learning, teaching, and understanding have not been convincingly answered. In addition, there are enormous difficulties in accurately representing the stages of student learning and in identifying possible misconceptions, facts that contributed towards a diversification in ITS-related research.

For Dede [11], the Intelligent Tutoring Systems and Trainers, also called Intelligent Computer-Aided Instruction (ICAI), provide educational technology with the characteristics of the teacher's cognitive skills. The strategies focused on these types of educational applications are based on ideas from the field of Artificial Intelligence. ITS/ICAI applications ideally contain dynamic models of the learner in which knowledge can be 
communicated and discussed pedagogically. These systems establish who, what and how to teach. In a full-fledged ITS, the material to be presented to the learner is interactively treated by these dynamic models, generated by the system in real time.

\section{A. ITS Architectures and Subsystems}

ITS architectures vary from one implementation to another. Numerous systems were implemented in the mid-1970s and 1980s by Clancey in 1979, Johnson in 1985, Anderson in 1985, and Viccari in 1990, among others [12]. The architecture developed during this phase proposed that an ITS/ICAI system should include the following functional elements, described from an analytical and critical perspective.

- An explicit domain model and an expert system capable of solving problems in that domain.

- An identification model with some detail about the student's knowledge of the domain.

- A teaching model that offers instruction, presenting instructional material, capable of detecting and assisting in the resolution of learners' misconceptions [13].

The structure of a system with the above characteristics requires the development of the tutorial system composed of the modules shown in Figure 1.

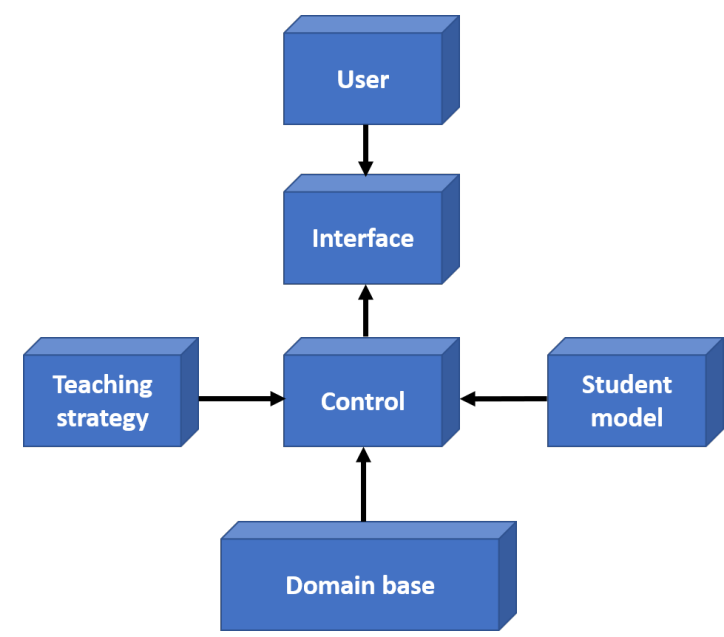

Fig. 1. General architecture of a ITS. Source: adapted from [9]

In the most recent conceptualizations of ITS [14], the emphasis on student modeling as the key to adaptive tutoring remains evident. Based on these papers and a review of the literature on ITS assessments, the following definition is adopted [3] [14]: An ITS is a computer system that for each student performs tutoring with various functions that:

- Present information for learning,

- Ask questions or assign tasks for learning,

- Make comments and/or suggestions,

- Answer questions asked by students,

- Establishes indications to provoke a cognitive, motivational or metacognitive change.
By establishing inferences from the student's responses, a persistent multidimensional model of the student's psychological states, such as subject knowledge, learning strategies, motivations or emotions, is constructed or the student's current psychological domain is established in a multidimensional domain model. The student-modeling functions identified in the previous point are used to make adaptations to one or more of the tutoring functions identified in the first point.

The different components of ITS architecture will be described below.

1) Knowledge domain base: The domain model [15], is the expert component of the tutor, the specialist who treats and manipulates the knowledge of the subject [16], constituted by the instructional material, by a systematic generation of examples, by the formulation of diagnoses and by the simulation processes. It contains the knowledge about the domain that we want to teach the student [4] [17].

This module would have the function of allowing the alteration/enlargement/adaptation of the tutor's two main knowledge-based components: the domain base and the student model. The inclusion of learning capabilities in the tutorial system [18], implies an architectural style that is not supported by bases of knowledge but based on beliefs.

Several knowledge representation models can be used in this module, among them: Semantic Networks, frames, scripts, production rules, Object Oriented Programming - OOP, among others. The selection should focus on the method that best and most easily meets the requirements of representation and manipulation of reasoning. Inadequate selection may compromise the system's performance, since this module must be able to determine, among other things, the complexity and consequently the way of presenting the concepts of the knowledge area in question. Instructional material is generally organized in a taxonomy that provides for increasing levels of complexity. The tasks are organized using a dynamically formed tree structure, according to the student's interaction and work [19]. The teaching strategy to be used will depend on the model of the defined student.

The domain knowledge base [20], is a key component of ITS, where the instructional material, i.e. the content that the tutor must provide, is represented. The fact that this content is stored in a knowledge base, and/or in a conventional database, is one of the factors that determine the difference between an ITS and a conventional CAI [21]. The knowledge base should enable the system to reason about the structure of the content to be provided, thus allowing it to take a more active role than presenting content in a linear fashion.

2) Student's model: This is the expert in teaching techniques [16], that selects the concepts, sets the levels of difficulty of the teaching activity and controls the level of the learning process. The student's model [12], contains the relevant information - from the tutor's point of view - about the student. It is the presence of this model that allows the tutor system to adapt to each student, customizing the instruction. This module represents the knowledge and cognitive skills of the student at a given moment.

It is constituted by static and dynamic data that will be of fundamental importance, so that the tutor can check 
the hypothesis with respect to the student [9]. It contains a representation of the student's state of knowledge at the moment that they interact with the ITS. From this model, the student manages the content to be taught and the system must be able to infer the best teaching strategy to be used next. A real model of the student implies a dynamic update as the system evaluates the student's performance. The dynamic data refers to the performance that the student has in relation to the questions formulated by the tutor and confronted with the hypotheses elaborated by the student, towards the use that the student makes of the system and towards the new knowledge that the student can receive from the tutor's teaching.

Some of the techniques that are used to build the student's model [19]:

- Include pattern recognition applied to the history of the responses provided;

- Compare the student's behavior with that of a specialist and verify the common points;

- Consider the student's preferences;

- Consider the student's particular goals;

- Things that tend to be forgotten when interacting with the tutor;

- Indication of their particular objectives.

The student model, according to Costa [22], can be represented using some description models, namely:

- Differential model: Where the student's response is compared to the knowledge base.

- Overlay model [19] The student's knowledge is represented as a subset of the tutor system's knowledge base [23] [24]. This model assumes (implicitly or explicitly) that the student's errors or abnormal behaviour are always due to the absence of some information present in the knowledge base of the domain. This psychological assumption is overly simplistic, as incorrect behaviour originates from the presence of misconceptions in the student's mind.

- The disturbance model or BUGGY model: also relates the model of the student in the knowledge base of the domain [25] [26]. The disturbance model assumes that the student's errors are derived from the misconception of some concept or lack thereof. For this case, there is the domain base and a typical error library; the student model includes elements of the domain base and error library as shown in Fig. 2.

- Simulation Model: The environment has a model of how the student can or should behave in a certain situation and through this model it is possible to foresee the future behavior of the student; in other words, the response of the student based on their behavior during the work session.

- Belief Model [27] consists of a set of beliefs that reflect the degree of understanding of the student regarding a particular concept. According to [19], it should refer to belief bases rather than knowledge

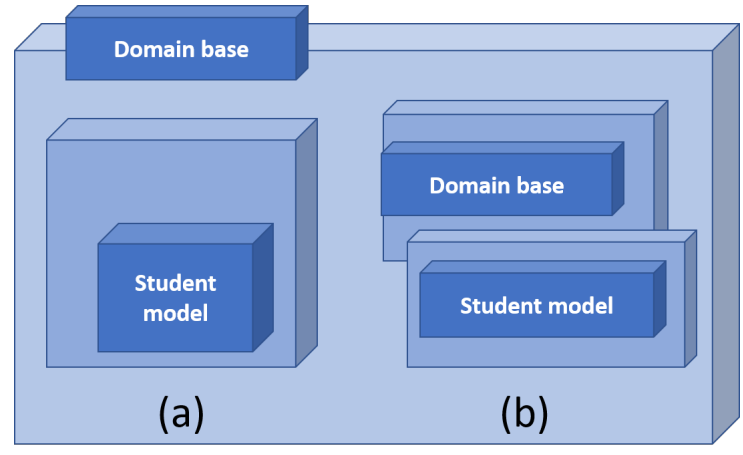

Fig. 2. Overlay Model. Source: adapted from [9]

bases, since the logical behavior of the student's conceptions is much more like a belief logic than a knowledge logic [28].

- Agent Model: When treating the student model as a belief system [9], an important notion is implicitly used: the interaction between the student and the tutor system is an interaction between two intelligent agents (or, at least, endowed with some cognitive behavior). Considering the student as an agent, implies considering the student's model as an agent model or that it will have consequences for the model's structure.

- Constraint Based Model (CBM). This was proposed for the first time, for the modelling of students in the short term and the diagnosis of the current state of the solution. CBM uses constraints to present student mastery and knowledge [23]. The process of diagnosing the student's solution is by matching the relevant conditions of all the constraints with the student's solutions. The condition of satisfaction for all relevance conditions must also be met. The system checks every step taken by the student, diagnoses any problems, and provides feedback to the student when there is an error. The feedback informs the student that the solution is wrong, indicating the part of the solution that is wrong, and then specifies the principle of mastery that has been violated [29].

Cognitive theories. As many researchers claim, the use of Human Plausible Reasoning (HPR) and Multiple Attribute Decision-Making (MADM) Theory for the purpose of student modeling [23] and diagnosing misconceptions, leads to the design and development of effective ITS. The cognitive theory approach helps to interpret human behavior during the learning process by trying to understand human thought and comprehension processes.

- Bayesian Networks - BN: Another well-known and established approach to representing and reasoning about uncertainty in student models is Bayesian Networks. A Bayesian network (BN) is a cyclical, directed graph containing random variables, which are represented as the network. Probabilistic relationships between variables are presented as arcs. The BN reasons about the situation it models, analyzing sequences 
of actions, observations, consequences and expected outcomes [30]. With respect to the learner model, learner components such as knowledge, misconceptions, emotions, learning styles, motivation, and goals can be represented as nodes in the BN.

- Fuzzy student modeling. The student's level of knowledge is established as a fuzzy problem. One possible approach to dealing with uncertainty is fuzzy logic, introduced by Zadeh in 1956 as a methodology for computing and reasoning with words representing imprecise values rather than numerical values. Fuzzy logic is used to deal with the uncertainty of realworld problems derived from inaccurate and incomplete data, as well as from human subjectivity. Fuzzy logic uses fuzzy sets that involve variables with uncertain values. The use of fuzzy logic can improve the learning environment by allowing intelligent decisions about the learning content to be delivered to the learner, as well as personalized feedback to be given to each learner. It is a fuzzy logic channel to diagnose the level of knowledge of the student in a concept and to predict the level of knowledge for other concepts related to that concept [31]. Some authors argue that the integration of fuzzy logic in the student's model increases student satisfaction and performance, improves the adaptability of the system and contributes to more reliable decision-making. The use of fuzzy logic in student modeling is becoming popular because it overcomes computational complexity, imitating human nature.

Finally, in 1994 Nwana [4], classified the students models into the following six different types:

- Corrective in which the elimination of misconceptions in the student's knowledge is allowed.

- Collaborative, in the student's report.

- A tool that helps the tutorials to adopt the action and the performance of the student.

- Diagnostic, which identifies the errors in the most recent student's knowledge.

- Predictive, which helps to understand the answers of the most recent client's evaluation system.

- The final objective evaluates the value of the student's overall progress.

The strategies constitute the knowledge on how to teach; in other words, how to generate from the diagnostic information, monitoring and analysis, a sequence of teaching tactics, capable of successfully presenting a certain topic to a certain student. According to Breuker [19], most authors agree that a teaching strategy must question:

- When to interrupt? What reasons justify interrupting the student's course of learning?

- What to say? This question is divided into:

- selection of the topic(s) to be presented

- ordering of the topics, if there is more than one
- How to say it? This is probably the most difficult question. No concrete general solutions have been proposed, and many authors here point out the lack of sufficiently detailed pedagogical theories.

3) Control model: The control module manages the operation of the tutor system. Its execution cycle can be characterized as follows [13]:

- Selection of a teaching strategy from the strategy bank;

- Based on the teaching strategy, select an instructional material from the domain's knowledge base;

- Present the material to the student through the interface module (which may include the presentation of exercises and solution of proposed exercises)

From the student's responses, diagnose their behavior and monitor their progress, reading/updating the student's model and restarting the cycle. This is the module responsible for the general coordination of the tutor regarding the functions, natural language interfaces, information exchange between modules and communication with other utility programs through the operating system.

Communication between the tutor modules consists of saving or reading files, keeping a historical file of the learning session, activating and deactivating the databases which can be conceived as "worlds" created from the interaction between the tutor and the student.

The ICAIs have a learning capacity in what refers to the alterations made in the tutor's role, resulting from the interaction process with the student. In some tutors, the initial core is not altered at the end of the session, restarting in the same way for any new user, while in other more refined models, each interaction or initial database is altered, so that the system evolves learning with each user and applying this new knowledge to each student.

4) Interface: This is the expert who interprets natural language [16]. It is established that a good interface is vital for the success of any interactive system and ITS are no exception. On the contrary, it can be said that the quality of the interaction grows in importance in this kind of system, because it is during the interaction that the tutor system exerts two of its main functions [13]:

- The presentation of the instructional material;

- The monitoring of the student's progress through the reception of the student's response.

From these two functions, some objectives can be derived to be fulfilled by the interface module [19]:

- It is necessary to avoid that the student perceive that the session is tedious; that is, the wealth of resources in the presentation of the instructional material is necessary;

- It is desirable that there be facilities for change in the dialogue initiatives: the student must be able to intervene easily in the tutor's discourse, and vice versa; 
- The response time must obviously remain within acceptable limits;

- $\quad$ Monitoring must be carried out as far as possible in the background, so as not to burden the student with questionnaires that could increase their workload, and also respecting the barrier of response time.

Since the incorporation to the systems of the resources offered by hypertext and hypermedia, the possibilities of quality in the presentation of the instructional material have received significant progress, being improved even further, with the incorporation of the emerging resources associated to technologies based on the Web. The variety of resources, associated with the possibility of reviewing the material in a way linked to the semantics of the content, makes hypermedia systems a high potential tool for the presentation of instructional material in ITS.

Monitoring of student progress occurs at two levels:

- At the level of historical student analysis, that is, from one session to the next.

- At the level of diagnosis limited to one session.

\section{CURRENT DEVELOPMENT IN ITSS IN COMPUTER AND WEB BASED EDUCATION}

Over the past few years, several effective and successful ITS have been proposed and mentioned in various parts of this paper. In this section, a review will be made of the different areas of research on which the research is focusing.

\section{A. Intelligent Adaptive Educational Systems}

Adaptive Intelligent Web-Based Systems (AIWBES) or adaptive hypermedia, are an alternative to the traditional approach that only provides the development of web-based educational courses. These systems offer a high degree of adaptability in terms of objectives, preferences, learning styles [32] [33] [34], and individual student knowledge during interaction with the system [35] [36] [37].

In the area of research, the first research was focused on adaptive educational hypermedia, which is the result of the incorporation of resources that combine educational hypermedia with ITS, providing greater flexibility and functionality than traditional static educational hypermedia [38]. Several systems have been developed under the AIWBES category, focusing on distance learning not only to provide support with textbook course material, but also to provide elements for problem solving. Adaptive navigation through the material was implemented to support individual student learning. An important attribute is that the system classifies the content of a page so that it is ready to be learned, or even if it is not ready to be learned because the prerequisites have not yet been worked with [39]. Additionally, links are ordered according to relevance to the current state of the student, so that students know which situations are most similar or which web pages are most relevant. When the student enters a page that contains a portion of prerequisite and knowledge to be learned, the system alerts the student to the prerequisite and suggests additional links to the textbook and textbook pages about them. Empirical studies have shown that hypermedia systems in conjunction with tutoring tools can be useful in supporting self-learning [40]. Some intelligent adaptive hypermedia systems that have been used by many students include Interbook [41] and the AHA! [42], which were designed to help students learn better and in less time [43].

\section{B. Cultural Awareness in Education}

In recent years, special attention has been paid to problems arising in the context of education in a globalized society [44]. Researchers are concerned about how learning technology systems can be adapted through cultural diversity. Nyein [45] addressed the barriers faced by ITS in the developing world. Barriers such as lack of computer skills of students, problems arising from multiple languages and cultures, etc. were presented along with existing solutions. Ogan et al. [44], conducted an analysis of learners' help-seeking behaviors regarding ITS in different cultures. Behavioral models of helpseeking behavior during learning have been developed based on data sets of students from different countries: Costa Rica, the Philippines and the United States. M. Mohan [46] takes the first step to avoid focusing on this problem. The root of this study provides students with some control over their cultural preferences, including the description of the problem, feedback, and the presentation of images and suggestions. The deployment of such systems has provided researchers with the opportunity to experiment with the phenomena surrounding the social acceptability of the use of non-dominant language in education, and has effects that should be further investigated.

\section{Collaborative Learning}

Research in contemporary education suggests that collaborative learning or group learning improves group learning performance as well as individual learning outcomes [47] [48]. In a collaborative learning environment, students learn in groups through interactions among themselves by asking questions, explaining and justifying their opinions, explaining their reasoning, and presenting to their peers topics of their knowledge [49]. Several researchers have pointed out the importance of having a group learning environment and how significant it can be in terms of improving learning [50]. Nowa-days, interesting implementations of collaborative learning in tutoring systems are emerging to show the benefits obtained from the interaction between students during problem solving, such as in the domain of engineering [20], in which teams of two or more students work on the same task when solving a problem. Also, a series of experiments were carried out to investigate the effectiveness of collaborative learning and how to involve students more deeply in the conversations of the instructional process with tutors, using teaching techniques such as attention focusing, question and answer and social interaction strategies. Students working in pairs were found to learn better than students working individually [47] [48].

\section{ITS with a Playful Focus}

ITS and their interactive components can be interesting when used for a short period of time (e.g., a few hours), but can become monotonous and boring or even annoying when a learner needs to interact with ITS for weeks or even months [51]. The idea behind play-based learning is that learners learn best when they find the teaching/learning 
activities fun by getting involved and participating in the learning process in an active way, and by motivating them to use the system longer [52]. Some researchers argue that the principles of ITS development approaches maximize learning and that play technologies maximize motivation. Instead of learning a subject with a conventional, traditional approach, students play an educational game that successfully integrates game strategies with curriculum-based content. Although there is no overwhelming evidence to support the effectiveness of educational systems that incorporate playful aspects which can take the form of games associated with computer tutors, educational games have been found to have advantages over traditional tutoring approaches [53] [54]. Finally, several studies found a strong relationship between learning outcomes, problem solving in play and increased engagement [55].

\section{SOME DEVELOPMENTS IN ITS'S}

In this section, various proposals for ITS architectures are reviewed and analyzed, including reviewing the results and evidence reported by the different research groups that proposed them.

Badaracco and Martinez [56], propose an ITS which has the objective of dynamically customising teaching processes according to the profile and activities of the student, using artificial intelligence techniques. In the proposal, the pedagogical model is crucial, because the complexity of the ITS will depend on their scope, which can be defined as specific or generic. This work proposes an architecture that uses a pedagogical model of learning based on competences, with the purpose of managing the complexity and facilitating its understanding, along with a diagnostic process for this system.

H. Al Rekhawi and S. Naser [57], propose the design of a web-based ITS system for teaching application development in an Android environment to help overcome the difficulties they face. The system introduces the topic of application development in Android and manages automatically generated problems for students to solve. In addition, automatic adaptations are made in relation to execution times, considering the individual growth of the student. The system provides support for the realization of constructions through adaptive demonstrations. An initial evaluation was conducted to examine the effect of the use of ITS on the performance of students in the development of applications for smart phones, obtaining results that showed a positive impact on evaluations.

M. Hamed. S. and Abu Naser [58], proposed an ITS system to facilitate the learning of science subjects at school level since, according to these authors, students face some learning problems. The system supports the understanding of these issues through analysis and explanation in a systematic way. The design of the ITS described is focused on the teaching of science for the 7 th grade, supporting students in the knowledge of characteristics of living beings, providing in addition all the topics related to living beings and generating some questions for each topic, to which the students must answer correctly, in order to pass to the next level. The authors carried out an evaluation to verify the satisfaction of the students and teachers who use their proposal. The results obtained in relation to the usefulness and usability of the system were satisfactory.
N. Gon, S. Bisw. and L. Ba But [59], report the development of an ITS for Multimedia Virtual Power Laboratory (VPL) which can simulate an electric machine laboratory. In the VPL architecture, which consists of instructional design and implementation of an ITS, the virtual lab is supervised by a virtual Smart Tutor who can track the students' progress and monitor their actions, on the virtual lab platform. The VPL offers a virtual experimental environment with 2D graphics, 3D animations, audio guidance, simulations, knowledge concept bases and virtual experiments, functionalities on which the ITS is designed. It can process user actions and existing resources in the lab, as well as track student progress by answering questions, monitoring their actions and, if necessary, guiding students through the contents of the previous material required for the mastery of the subject.

W. Yu-Ying [60], propose an ITS to support students in improving their English skills. The aim of the system is to provide a tutorial environment where teachers and students do not need to prepare much teaching and learning support material by teaching or learning English in that environment. An interesting element of the proposal is the verification method of the intelligent tutoring system, using Petri dishes. The ITS was developed in an Augmented Reality (AR) environment, a Text to Speech (TTS) and Speech Recognition (SR) system. The system is divided into two parts: one for teachers and one for students. The reported experimental results show that the use of Petri dish networks can support users in the verification of the intelligent tutoring system for better learning performance and correct operation.

The authors W. Ma, O. J. Nesbit, Q. Liu. O and Adesope [3], conducted a meta-analysis regarding research that compared the learning outcomes of students who learned using ITS with those who learned from learning environments that did not include ITS. The meta-analysis examined how the magnitudes of effects varied according to the type of ITS, the type of comparative treatment received by the learners, the learning outcome, and whether the knowledge to be learned was procedural or declarative, as well as other factors. The use of ITS was associated with higher performance compared to teacher-led instruction for large groups of students, noncomputerized ITS-based instruction, and textbooks or workbooks. There were no significant differences between learning using ITS and learning through individualized human tutoring or small group instruction. Significant positive average effect sizes were found regardless of whether ITS were used as the primary means of instruction, a supplement to teacher-led instruction, an integral component of teacher-led instruction, or a homework aid. Significant positive effect measures were found, at all levels of education, in almost all subject domains assessed, and whether or not ITS provided erroneous student feedback or models. The research claim made in this paper that ITS are relatively effective tools for learning is consistent with the studies and analyses conducted by these authors.

Likewise, the research carried out evidences that the ITS developed at the moment constitute effective tools for the activities of teaching learning, due to which they count on a high degree of adaptation to the demands and interests of the students, this in part because they consider elements like the styles of learning, the individual differences, the levels of advance in the learning, among other attributes and also to 
the use of techniques of Artificial Intelligence and emergent resources associated to the Virtual Reality, Augmented Reality and Multimedia, among others.

\section{DISCUSSION}

ITS were designed with the objective of having a degree of adaptation to the characteristics and special requirements that students demand, individually. The ability to track the individual cognitive states of students in order to provide an appropriate response is what differentiates ITS from other educational systems. Likewise, the ITS focused the attention of researchers from various disciplines such as Psychology, Cognitive Sciences, Educational Sciences and especially Computer Science. These systems aim to achieve the possibility of imitating expert human tutors in the way they teach and interact with students. Throughout the last decades, ITS have demonstrated their pedagogical effectiveness, contributing with the improvement of students' learning results. It is likely that their systems will be useful for adults or children with special needs in the pursuit of their learning goals, as they can be effective and helpful in supporting the teaching of people with cognitive disabilities such as dyslexia, attention deficit disorder and dyscalculia, among others.

Also, many benefits can be obtained from research in this line of investigation, since there are hundreds of ITS software applications for a variety of subject domains, and these applications can be extended to other disciplines.

Research and findings in this direction could increase the popularity of ITS as a new educational tool approach in order to support students in their decisions regarding which majors to choose.

Finally, they can also provide subsidiary support over time to significantly improve students' competencies and skills and prepare them for other stages of their lives.

\section{CONCLUSION AND COMMENTS}

It is important to note that despite important developments in ITS, the differences between human tutors and ITS are numerous. The role of ITS is therefore to support learners and human tutors in teaching and learning activities.

Various models were developed for the representation of knowledge, teaching styles and student knowledge. The different models have advantages and disadvantages. The reviews conducted concluded that in some circumstances, the use of ITS allows better results than traditional classroom instruction and study in printed materials.

Hybrid models were designed to improve and strengthen traditional models. There are many unanswered research questions regarding the principles of human thinking and learning, such as those from approaches in Cognitive Biology, Psychology, Educational Sciences, Neurosciences, and others. Many of these approaches, their methodologies and techniques, have been incorporated into ITS, and have been implemented and tested with certain levels of success.

ITS may become a competitive alternative for humans in the future, considering aspects of cost, time and levels of application at scale. ITS promise to standardize and implement aspects of human learning as much as possible, but they still have many limitations to overcome.

The convergence of ITS with AI and psychology in research teams, promises continued progress in the development of ITS research.

\section{ACKNOWLEDGMENT}

The authors would like to thank Saint Augustin National University (UNSA) - Arequipa - Peru, Catolic University of Santa María - Peru and the Federal University of Santa Catarina - Florianópolis - Brasil

\section{REFERENCES}

[1] J. Carbonell, AI in CAI: An artificial intelligence approach to computer assisted instruction. IEEE Transactions on Man-Machine Systems,vol.11, no.4, pp.190-202, 1970.

[2] B. Woolf, Building intelligent interactive tutors: Student-centered strategies for revolutionizing e-Learning. Morgan Kaufmann, 2010.

[3] W. Ma and O. Adesope and J. Quing and Q. Liu, Intelligent Tutoring Systems and Learning Outcomes: A Meta-Analysis. Journal of Educational Psychology 2014 American Psychological Association 2014, Vol. 106, No. 4, 901-918.

[4] H.S. Nwana, Intelligent tutoring systems: an overview. Artificial Intelligence Review, vol.4, no.4, pp.251-277, 1990.

[5] V. Shute and J. Psotka, Intelligent tutoring systems: Past, present, andfuture. DTIC. Document, Tech.Rep., 1994.

[6] T. Murray, An overview of intelligent tutoring system authoring tools: Updated analysis of the state of the art. in Authoring tools for advanced technology learning environments. Springer, 2003, pp.491-544.

[7] E. Aimeur and C. Frasson, Analizing a new Learning strategy according to different konowledge levels. Computers Education. Vol. 27, No. 2.

[8] L. Alfaro, Contribuições para a modelagem de um ambiente inteligente de educação baseado em realidade virtual. Doutorado. Programa de Pós-Graduação em Engenharia de Produção. Universidade Federal de Santa Catarina, Brasil, 1999. Brasil.

[9] L.M.M. Giraffa and M.A. Nunes and R.M. Viccari, Multi-Ecological: an Intelligent Learning Environment using Multi-Agent architecture. MASTA'97: Multi-Agent System: Theory and Applications. Proceedings. Coimbra: DE-Universidade de Coimbra, 1997.

[10] T. Dillenbourg, Intelligent Learning Environments. Carouge - Switzerland. TECFA (Technologies de Formation et Apprentissage). Faculté de Psychologie et des Sciences de l'Education. University of Geneva (Switzerland), 1993. 34 p.

[11] C. Dede and M. Salzman and C. Loftin and R. Bowen, ScienceSpace: Virtual realities for learning complex and abstract scientific concepts. 1995. http://www.virtual.qmu.edu/vriaspdf.htm

[12] L. Giraffa, Selecting teaching strategies using pedagogical agents. Porto Alegre, 1998. Proposta de tese (Doutorado em Ciência da Computação. Instituto de Informática) Universidade Federal do Rio Grande do Sul. 77 P.

[13] F. Oliveira, Critérios de equilibração para sistemas tutores. Porto Alegre, 1994. Tese (Doutorado em Ciencia da Computação. Instituto de Informática) Universidade Federal do Rio Grande do Sul. Brasil. 68 p.

[14] R. Sottilare and A. Graesser and X. Hu and H. Holden (Eds.), Design recommendations for Intelligent Tutoring Systems. Orlando, FL: U.S. Army Research Laboratory. 2013. ISBN: 978-0-9893923-0-3.

[15] R. Mizoguchi, Student modeling in ITS. Emerging Technologies in Education, vol.8, pp. 35-48, 1995. 68 p.

[16] M. Corredor, Sistemas tutoriales inteligentes. Boletín de Informática Educativa. Colombia. Proyecto SIIE. Vol. 2, No 1. 1989.

[17] E. Sierra, Towards a methodology for the design of intelligent tutoring systems. Research in Computing Science Journal, vol. 20, pp.181-189, 2006. 
[18] R. Nkambou, Modeling the domain: An introduction to the expert module. in Advances in Intelligent Tutoring Systems, ser. Studies in Computational Intelligence, R. Nkambou, J. Bourdeau, and R. Mizoguchi, Eds. Springer Berlin Heidelberg, 2010, no. 308,pp. 15-32.

[19] L. Giraffa, Seleção e adoção de Estratégias de Ensino em Sistemas Tutores Inteligentes. Porto Alegre, 1997. Exame de Qualificação (Doutorado em Ciência da Computação. Instituto de Informática) Universidade Federal do Rio Grande do Sul. 127 P.

[20] F.S. Gharehchopogh and Z.A. Khalifelu, Using intelligent tutoring systems in instruction and education. in 2nd International Conference on Education and Management Technology, vol. 13. IACSIT Press Singapore, 2011, pp. 250-254.

[21] F.M. Oliveira and R.M. Viccari, Are learning systems distributed or social systems?. EUROPEAN CONFERENCE ON ARTIFICIAL INTELLIGENCE IN EDUCATION, I, Lisboa - Portugal. 1996.

[22] E.B. Costa, Um modelo de Ambiente Interativo de Ensino-Aprendizagem baseado numa Arquitetura Multi-Agentes. Campina Grande, 1997. Exame de Qualificação (Doutorado CPGEE), UFPA. SP - Brasil.

[23] K. Chrysafiadiand and M. Virvou, Student modeling approaches: A literature review for the last decade. Expert Systems with Applications, vol.40, no.11, pp. 4715-4729, 2013

[24] C. Carmona and R. Cornejo, A learner model in a distributed environment. in Adaptive Hypermedia and Adaptive Web-Based Systems. Springer, 2004, pp. 353-359.

[25] A. Martins and L.C. Faria and E. Carrapatoso, User modeling in adaptive hypermedia educational systems. Journal of Educational Technology \& Society, vol.11, no.1 ,pp. 194-207, 2008

[26] L. Nguyenand and P. Do, Learner modeling adaptive learning. World Academy of Science, Engineering and Technology, vol. 45, pp. 395-400, 2008.

[27] E. Rich, Stereotypes and user modeling in User Models. in Dialog Systems, ser. Symbolic Computation, A.Kobsaand W.Wahlster, Eds. Springer Berlin Heidelberg, 1989, pp.35-51.

[28] J. Kay, Stereotypes, student models and scrutabilit. in Intelligent Tutoring Systems, Lecture Notes in Computer Science, G. Gauthier, C. Frasson, and K.V. Lehn, Eds. Springer Berlin, no.1839, pp.19-30.

[29] A. Mitrovic, Fifteen year sof constraint-based tutors: what we have achieved and where weare going. UserModeling and User-Adapted Interaction, vol.22, no.1-2, pp.39-72, 2012.

[30] E. Millan and T. Lobo and J. Perez-de-la-Cruz, Bayesian networks for student model engineering. Computers \& Education, vol. 55, no.4, pp.1663-1683, 2010.

[31] M. Danaparamita and F. Gaol, Comparing Student Model Accuracy with Bayesian Network and Fuzzy Logic. in Predicting Student Knowledge Level. International Journal of Multimedia and Ubiquitous Engineering, vol.9, no.4, pp. 109-120, 2014.

[32] L. Alfaro and C. Rivera and J. Luna-Urquizo, Using Project-based Learning in a Hybrid e-Learning System Model. (IJACSA) International Journal of Advanced Computer Science and Applications, Vol. 10, No. $10,2019$.

[33] L. Alfaro and C. Rivera and J. Luna-Urquizo, Utilization of a Neuro Fuzzy Model for the Online Detection of Learning Styles in Adaptive e-Learning Systems. (IJACSA) International Journal of Advanced Computer Science and Applications, Vol. 9, No. 12, 2018.

[34] L. Alfaro and E. Apaza and J. Luna-Urquizo and C. Rivera, Identification of Learning Styles and Automatic Assignment of Projects in an Adaptive e-Learning Environment using Project based Learning. (IJACSA) International Journal of Advanced Computer Science and Applications, Vol. 10, No. 11, 2019.

[35] S. Blessing and S. Gilbert and S. Ourada and S. Ritter, Authoring model tracing cognitive tutors. International Journal of Artificial Intelligence in Education, vol. 19, no.2, p.189, 2009.

[36] A. Flores and L. Alfaro and J. Herrera and E. Hinojosa, Proposal Models for Personalization of e-Learning based on Flow Theory and Artificial Intelligence. (IJACSA) International Journal of Advanced Computer Science and Applications, Vol. 10, No. 7, 2019.

[37] A. Flores and L. Alfaro and J. Herrera, Proposal model for e-learning based on Case Based Reasoning and Reinforcement Learning.. In IEEE World Conference on Engineering Education (EDUNINE), 2019.
[38] P. Brusilovsky, Adaptive hypermedia: From intelligent tutoring systems to web-based education. in Intelligent Tutoring Systems, ser. Lecture Notes in Computer Science, G. Gauthier, C. Frasson, and K.Van Lehn,Eds. Springer Berlin Heidelberg, 2000, no.1839, pp.1-7, 2000.

[39] P. De-Bra, Adaptive educational hypermedia on the web. Communications of the ACM, vol.45, no.5, pp.60-61, 2002.

[40] J. Eklund and P. Brusilovsky, The value of adaptivity in hypermedia learning environments: A short review of empirical evidence. in Proceedings of 2nd Adaptive Hypertext and Hypermedia Workshop at the 9th ACM International Hypertext Conference Hypertext, vol.98, 1998, pp. 11-17.

[41] J. Eklund and P. Brusilovsky, Interbook: an adaptive tutoring system. Uni Serve Science News, vol.12, no.3, pp.8-13, 1999.

[42] D. Braand and L. Calvi, Aha! an open adaptive hypermedia architecture. New Review of Hypermedia and Multimedia, vol.4, no.1, pp.115-139, 1998.

[43] P. Brusilovsky, Adaptive hypermedia for education and training, iaptive Technologies for Training and Education. Cambridge University Press, 2012, pp.46-68.

[44] A. Ogan and W. Johnson, Preface for t the especial issue on culturall $y$ aware educational ntechnologies. Artif Intell Educ, vol. 25, pp.173-176, 2015.

[45] B.D. Nye, Intelligent tutoring systems by and for the developing world: a review of trends and approaches for educational technology in aglobal context. International Journal of Artificial Intelligence in Education, vol.25, no.2, pp.177-203, 2015.

[46] P. Mohammed and P. Mohan, Dynamic cultural contextualization of educational content in intelligent learning environments using icon. International Journal of Artificial Intelligence in Education, vol.25, no.2, pp.249-270, 2015.

[47] N. Dowell, What works: Creating adaptive and intelligent systems for collaborative learning support. International Journal of Artificial Intelligence in Education, vol.25, no.2, bpp.177-203, 2015.

[48] Y. Lou and P.C. Abrami and S. Apollonia, Small group and individual learning with technology: A meta-analysis. Review of educational research, vol.71, no.3, pp.449-521, 2001.

[49] A. Soller, Supporting social interaction in an intelligent collaborative learning system. International Journal of Artificial Intelligence in Education (IJAIED), vol.12, pp.40-62, 2001.

[50] Y. Hayashi, Togetherness: Multiple pedagogical conversational agents as companions in collaborative learning. in Intelligent Tutoring Systems, ser. Lecture Notes in Computer Science, S.Trausan Matu, K.E.Boyer, M.Crosby, and K. Panourgia, Eds. Springer International Publishing, 2014 , no. 8474, pp. 114-123.

[51] B. Kyun and B. Young, Gaming for Classroom-Based Learning: Digital Role Playing as a Motivator of Study. IGI Global, 2010.

[52] A. Raut and S.D.A. Uroojussama and U. Farheen and A.Anwari, Game based intelligent tutoring system. International Journal of Engineering Research and General Science, vol.3, no.2, 2015.

[53] M. Easterday and V. Aleven and R. Scheines and S.Carver, Using tutors to improve educational games. in Artificial Intelligence in Education, Lecture Notes in Computer Science, G. Biswas, S. Bull, J. Kay, and A. Mitrovic, Eds. Springer Berlin 2011 , no. 6738, p p. 63-71.

[54] G. Jackson and D. McNamara, Motivational impacts of a game-based intelligent tutoring system. in 24th International FLAIRS Conference, 2011.

[55] J. Lester, Serious games get smart: Intelligent game-based learning environments. AI Magazine, vol.34, no.4, pp. 31-45, 2013.

[56] M. Badaracco and L. Martínez, An Intelligent Tutoring System Architecture for Competency-Based Learning. A. König et al. (Eds.): KES 2011, Part II, LNAI 6882, pp. 124-133, Springer-Verlag Berlin, 2011

[57] H. Al-Rekhawi and S.A. Naser, An Intelligent Tutoring System for Learning Android Applications UI Development. International Journal of Engineering and Information Systems (IJEAIS) ISSN: 2000-000X Vol. 2 Issue 1, January - 2018, Pages: 1-14

[58] M. Hamed and S.A. Naser, An intelligent tutoring system for teaching the 7 characteristics for living things. International Journal of Advanced Research and Development ISSN: 2455-4030, Volume 2; Issue 1; January 2017; Page No. 31-35 
[59] N. Gon and S. Biswa and L. Ba, An Intelligent Tutoring System for Multimedia Virtual Power Laboratory. ASEE's 123rd Annual Conference \& Exposition. New Orleans, LA. June 26-29, 2016
[60] W. Yu-Ying, Modeling and verification of an intelligent tutoring system based on Petri net theory. Mathematical Biosciences and Engineering Volume 16, Issue 5, 4947-4975. 